\title{
A novel approach to in-depth façade assessments: Improved corrosion test methods for embedded steel framing in historic masonry clad buildings
}

\author{
Gina Crevello ${ }^{1,}$, Irene Matteini ${ }^{1}$, and Paul Noyce ${ }^{1}$ \\ ${ }^{1}$ Echem Consultants LLC, 4 Jefferson Plaza, Ste 500, Poughkeepsie, NY, USA
}

\begin{abstract}
Corrosion of structural steel frames and associated steel assemblies within 'vintage' buildings circa 1880 s to 1930 s pose a health and safety risk to the public in major urban centers. The projecting masonry elements pose a particular concern when the underlying steel assemblies and anchorage begin to corrode. Failed masonry has fallen from buildings, leading to death in worst case scenarios. While some signs of masonry cracking or displacement are usually visible prior to failure, the level of degradation of the embedded steel is not. With the equipment available to test these unforeseen conditions, methodologies need to be shifted to understand unobservable conditions to assist in condition state ratings of embedded steel. In many cities, building owners are being faced with large expenditures to strip and replace terra cotta or stone elements where the underlying steel is in fair condition. This paper will discuss the field-testing programs where a building elevations' masonry clad, steel assemblies (outriggers, anchorage and cross bracing) were evaluated for corrosion. The testing program assessed various steel components which either projected from the structure or were embedded at great depth with a bespoke, in-depth advanced testing program geared towards the development of condition state ratings for the façade elements.
\end{abstract}

\section{Introduction}

Corrosion of embedded structural steel in masonry clad buildings can lead to extensive maintenance and repair costs to the owner, the loss of structural integrity of the corroding members, and can pose life safety issues to pedestrians should masonry fall from overhead. Often, the results of corrosion related damages to masonry cladding are evident on the façade, however the degree of internal degradation of the steel is unknown. Traditional methods of material analysis include visual inspections and sounding surveys to determine quantifiable damage to the cladding, non-destructive evaluations to understand cracking of the masonry, and water infiltration and laboratory testing to determine material performance properties of the masonry units. Stripping of masonry for probes to allow observations of the steel typically occurs when investigating steel frame conditions, but is often limited due to the time, cost and destructive nature of probing. In-depth corrosion testing programs can provide ample support to understand condition of the underlying steel.

A façade evaluation of masonry clad steel framing and associated embedded steel assemblies, can be an invaluable tool. Corrosion testing programs allow the owners and design team an understanding of complex conditions within the building envelope which are often unseen during a traditional inspection. In addition, condition states related to corrosion activity can be categorized, and corrosion related degradation can be modelled based on the building's microclimates and corrosion rate. The resulting analysis provides a correlation of the unobserved conditions with steel section loss, which minimizes destructive investigations and can provide categorizations of future corrosion conditions. The knowledge gathered allows the team to make proactive repair choices on established corrosion condition states and helps budget funding based on anticipated degradation.

This paper will focus on terra cotta clad steel frame assessments.

\subsection{Steel Frame and Terra Cotta Construction}

\subsubsection{History}

Steel frame construction was prolific from the 1880 s to the 1930s, allowing designers and builders to achieve great heights in construction. This common construction method was chosen for fire resistance, durability and efficiency while the great selection of façade stones allowed for creative expression and architectural beauty to be achieved. While cladding types included granite, marble, limestone, porphyry, terra cotta became an ideal building material because of its fireproof, lightweight (lighter than cast or carved stone), and high compressive strength properties, and its ability to be easily molded and manufactured at a faster rate than stone could be carved. It could be used to mimic more expensive stone and the use use of glazing allowed for a wide color range 
for material selection, further enhancing terra cotta's versatility and waterproofing qualities.

In addition to structural steel framing Terra cotta cladding is typically four to eight inches in depth with some masonry units being greater in size. Brick is the typical infill material between the façade cladding and the steel frame. In most instances, a form of protection to the steel was utilized: lead paint, asbestos paper, or a cementitious parge coat. Corrosion of the steel had been observed and commented on as early as the 1894, by American architect George Post. During the demolition of the Tower Building in 1914, twenty-six years after construction, severe corrosion was noted, but it was dismissed and assumed to be caused by defective flashing.(1) Early engineering did not focus on material durability nor did construction details fully address moisture management, corrosion of the steel frame and associated steel assemblies . As the construction industry embraced these new systems, advances were made to improve building envelope performance.

Construction detailing became standardized by the National Terra Cotta Society first in 1914, and again in 1927. By 1927, further details were developed in relation to material performance, accounting for expansion of the terra cotta, structural failure, and water management within the building envelope. Shelf supports, provisions for movement, free standing construction, and flashing and drips were the most important principles upon which the standard was revised. It was also noted that proper care should be exercised to prevent corrosion of all steel supports and ties. Where such protection cannot be permanently secured through mortar or concrete, or with corrosion resistant metallic coatings, non-corrosive metals should be employed. (2)

\subsubsection{Deterioration Mechanisms}

The underlying causes of distress must be understood, so that a durable repair and appropriate maintenance program can be established.(3) Common modes of material failure for terra cotta include glaze and surface erosion, stress cracking from expansion, and deterioration caused by faulty craftsmanship.(4) Most deleterious to the material is corrosion of the anchorage and steel frame. Other than craftmanship defects, moisture ingress is a leading cause of the pervasive deterioration of terra cotta systems. Moisture penetrates the building envelope through failed joints, failed glazing, eroded surfaces caused by caustic cleaning or glaze (5) degradation from atmospheric contaminants, or other waterproofing failures of the building envelope.

The amount of water that penetrates a building increases as façade deterioration occurs. Moisture migration and movement through the building envelope of glazed terra cotta systems are prone to trapping moisture. This is due to the highly resistive and impermeable surface layer of the vitrified glaze, narrow mortar joints between units, and lack of weeps within the assembly. The material properties of the fired clay terra cotta body can retain moisture, keeping the infill and terra cotta unit damp. Retained moisture can lead to glaze spalling, cyclic freeze/thaw issues, and corrosion of the reinforcing steel.

Moisture and oxygen in the building envelope will incite corrosion of the steel frame and anchorage. This in turn cracks the masonry. As the cracks open, more oxygen and airborne particulates can reach the embedded steel. This increases rates of oxidation. Cracking caused by the accumulation of corrosion scale can destabilize terra cotta to the point of failure, leading to spalls and falling units. (6)

\subsubsection{Understanding Time Frames for Failure}

The greatest risk to façade deterioration is corrosion of the embedded steel frame and associated assemblies. A key advancement in understanding building envelope performance is the ability to forecast corrosion condition states through extensive, in-depth façade testing programs. This methodology has been successfully applied to steel frame buildings, in particular, those clad in terra cotta and glazed brick. To establish corrosion condition states adequate data is required, with a correlation and calibration of the data to the embedded steel. Observations are required though once visual conditions and corrosion data have been correlated, the testing programs become minimally invasive.

\subsection{Case Study}

To date this testing procedure has been performed on mass masonry wall systems with isolated, concrete encased steel members, independent armatures, full steel framing (electrically continuous), and on building systems with limestone, sandstone, granite and terra cladding. It is especially effective for glazed terra cotta and granite which are highly resistive materials. For this reason, a terra cotta façade is the subject of the case study.

\subsubsection{Project Introduction}

The subject building is located on the Upper West side of Manhattan in a historic district. While the building itself is not landmarked, it contributes to the historic character of the neighbourhood. The building was constructed in 1914, and designed by architects Gaetano Ajello and Rosario Candela, two of the most prominent pre-war luxury apartment building architects in NYC.

The building is thirteen stories in height. The exterior, street facing facades comprise a granite base, glazed brick cladding, decorative terra cotta balconies, balconettes, water tables, and a decorative terra cotta cornice. A character defining feature of the building is the Juliette balconettes which adorn the façade, yet also pose a high risk for failed masonry deficiencies if deteriorated.

During the local law inspection, by others, the Engineer of Record (EOR) for the inspection deemed that all the balconettes were unsafe. This would require stripping and replacement of all elements based on 
limited inspections. The associated costs with this work was approximately \$2 million USD. Prior repair work had been carried out on some of the balconettes, where a cementitious parge was applied over damaged terra cotta. This and the noted ingress of moisture from leaking air conditioning units was causing deterioration of the steel outriggers which support the terra cotta balconette tiles.

Due to this widespread approach of full replacement, the owner of the building engaged the authors to establish the condition of the embedded steel, to determine efficacy of cathodic protection and to prioritize repairs based on steel condition states.

\subsubsection{Testing Program}

The testing program was developed to test the balconette outriggers and the cornice outriggers. The balconette outrigger testing program is the subject of the condition state modeling for the purposes of this paper and information on the visual inspection has not been presented for brevity.

The objectives were to:

- Understand the mechanisms of deterioration of the steel sub-component

- Determine sub-components' condition and remaining lifecycle through a condition state process

- Determine the feasibility of corrosion control systems (impressed current)

- Provide a budget and recommendations for the findings

The team utilized condition states to help understand where the materials were in their overall lifecycle and to provide a structured method of analyses for different materials, conditions or components. This is an excellent method for comparing large quantities of structural components to improve financial decision making based on in-depth understanding of long-term performance (8).

\subsubsection{Methodology}

For the testing program, a bespoke modified linear polarization resistance test method was utilized to test the corrosion activity at the cantilever position of the outrigger within the building façade. Downhole corrosion rate testing was performed at three depths within the building envelope, surrounding the outriggers or critical steel component. These depths were three inches $(75 \mathrm{~mm})$, six inches $(150 \mathrm{~mm})$ and 10 inches (ca $250 \mathrm{~mm}$ ). The purpose of testing within the building envelope was to gather meaningful data within two inches $(50 \mathrm{~mm})$ of the embedded steel and at depths critical to the performance of the cantilevered steel. As this testing was "in-wall" it was deemed 3D versus traditional surface applied testing. Surface applied testing for glazed terra cotta and glazed brick is largely dependent on the surface ratio of the mortar joint to the probe head due to the highly resistive vitrified glaze. Testing within the wall cavity allows for readings that are closer to the steel and representative of the steel environment which impacts steel degradation.

The building has a total of twenty-four balconettes and four balconies equally split across the East and North elevation which are constructed from terracotta. In addition to this, the decorative cornice at the parapet stands 4'3" tall (ca 1.3m) and comprises five terra cotta masonry courses. There are sixty supportive and projecting modillions on the east elevation and fifty-two on the north elevation.

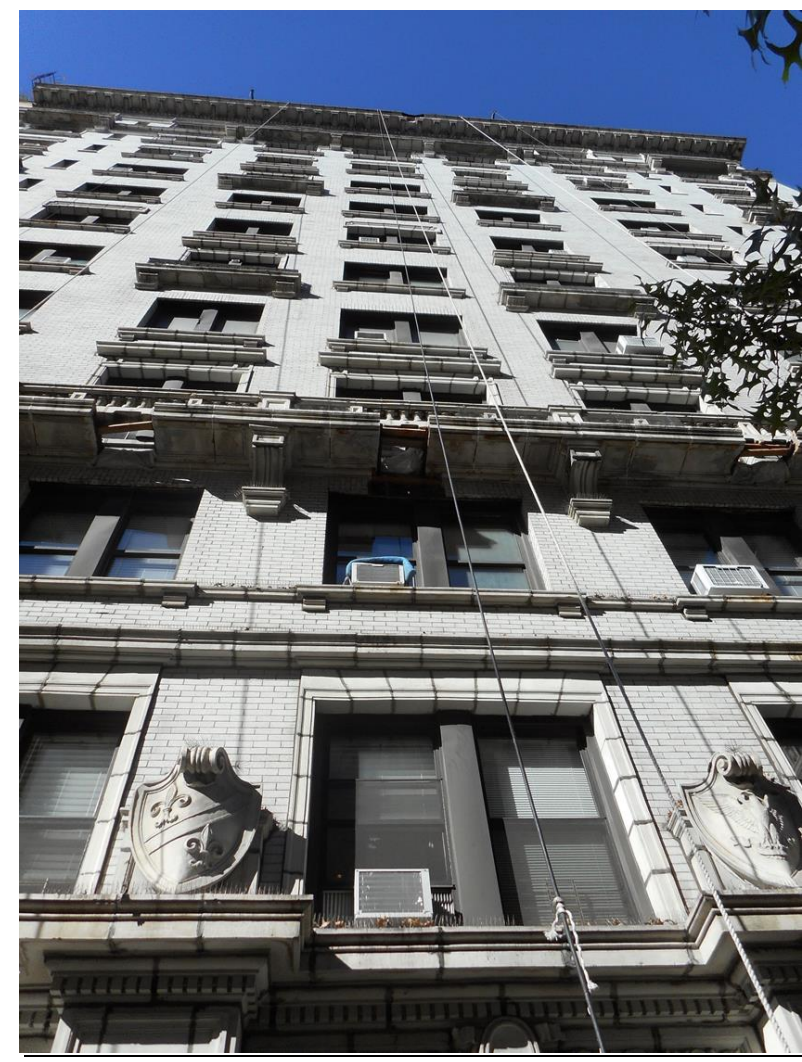

Fig. 1: Projecting Terra Cotta Façade Elements.

All of these subcomponents were included within the inspection and consist of equal sized terra cotta pieces for the balconettes (168 in total), different sizes for the balconies across both elevations (30 North, 42 East and 112 pieces for the cornice (Modillion).

A total of three hundred and twenty embedded steel subcomponents are supporting these terracotta pieces across the building as shown in Table 1 .

\subsubsection{Service Life Classification}

The building was categorized as a Class II structure at medium risk of corrosion and material degradation based on function, environmental exposure and construction material. This addresses temperature, contaminants and the building location for assessment purposes. 


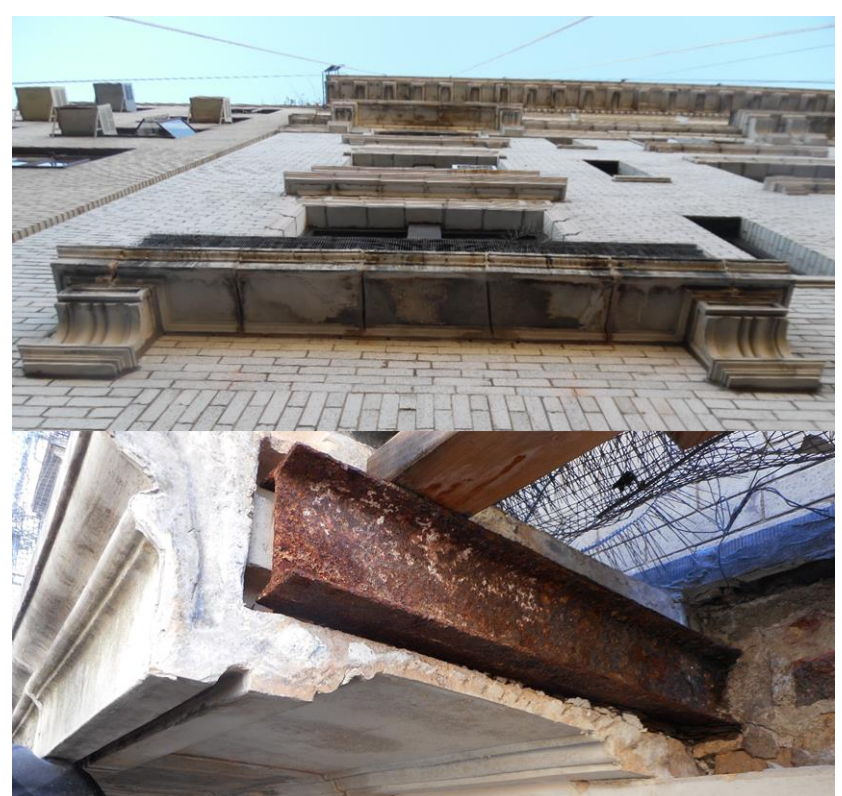

Fig. 2. (Top) Terra Cotta Balconettes. Fig. 3. (Bottom) Exposed Corroding Outrigger.

Table 1. Test Components

\begin{tabular}{|c|c|c|}
\hline Type & Quantity & Total \\
\hline T-Section & 6 per balconette & 144 \\
\hline I-Section & $\begin{array}{c}\text { 14 per balcony on } \\
\text { the North } \\
\text { elevation }\end{array}$ & \multirow{2}{*}{64} \\
\cline { 2 - 2 } & $\begin{array}{c}18 \text { per balcony on } \\
\text { the East elevation }\end{array}$ & \\
\hline $\begin{array}{c}\text { Double L- } \\
\text { Section }\end{array}$ & $\begin{array}{c}\text { 60 at the cornice } \\
\text { on the East } \\
\text { elevation }\end{array}$ & \multirow{2}{*}{112} \\
\cline { 2 - 2 } & $\begin{array}{c}\text { 52 at the cornice } \\
\text { on the North } \\
\text { elevation }\end{array}$ & \\
\hline \multicolumn{2}{|c|}{ Total } & 320 \\
\hline
\end{tabular}

The building falls under medium risk primarily due to its location and the vulnerability of contamination in the form of airborne chloride ions and carbon dioxide (carbonation) problems due to its age and exposure.

In order to understand the long-term durability of the structure, a condition state rating system was utilized which defines the current condition of the structure with regard to its degradation. This then provides a time frame for critical failures and the ability to demonstrate how repairs will provide a condition state extension, or when the structure components require replacement. Service life extension can be demonstrated based on what method of repair is utilized.

Technical Service Life, Functional Service Life and Economic Service Life are all means of assessing a structure as it ages and nears critical thresholds that reduce capacity or functionality. The technical service life for corrosion of the embedded steel can be defined on a five (5) state basis as follows:
Table 2. Interpretation of Condition States for Corrosion

\begin{tabular}{|c|c|l|}
\hline $\begin{array}{l}\text { Condition } \\
\text { State }\end{array}$ & $\begin{array}{l}\text { Section } \\
\text { Loss (\%) }\end{array}$ & Comments \\
\hline 5 & $<1$ & Very Low \\
\hline 4 & $1-9$ & Low to Medium \\
\hline 3 & $10-17$ & Medium \\
\hline 2 & $18-25$ & Medium to High \\
\hline 1 & $>25$ & Very High \\
\hline
\end{tabular}

The rationale for the condition states for corrosion of the embedded outriggers was the correlation of actual section loss observed and correlated with the measured corrosion rate values from the testing program. The Life $52 ®$ service life modelling system utilized provided the basis of the corrosion assessment by utilizing a five (5) state system based around section loss of the steel subcomponent. As more steel section is lost the condition state changes from one to another. This method of approach allows for the development of models where the amount of section loss can be determined with time, ultimately changing states. The condition states are then correlated with limit states, as seen in Table 3.

When condition state 2 is met the sub-component is said to be at its' limit and any additional section loss will ultimately lead to obsolescence. In this instance, obsolescence is not necessarily defined as structurally deficient, but so far progressed in the deterioration curve that repair, and rehabilitation become financially impractical to implement. The limit states are also influenced by the risk factors affecting the concrete or masonry, and the financial implications of the cost of deterioration to the owner.

Although the best approach is to be able to measure section loss of the actual component this is often impossible to carry out due to the physical amount of work required to access the sub-component. As a result of this, the approach was to use a combination of inspection methods enabling the inspection team to create a site-specific condition state table utilizing the test results obtained. By knowing the condition state of each sub-component, repair work can be planned accordingly with the ultimate aim of being more cost effective.

The condition state classification of the embedded steel sub-component has been based around the corrosion rate data recorded under the investigative work on site. Table 3 is unique to each structure and developed based on test results and visual observations.

Table 3. Corrosion Condition States and Limit States

\begin{tabular}{|c|c|c|c|}
\hline $\begin{array}{c}\text { Condition } \\
\text { State }\end{array}$ & $\begin{array}{c}\text { Corrosion } \\
\text { Rate } \\
(\mu \mathrm{m} / \mathrm{yr})\end{array}$ & $\begin{array}{c}\text { Section } \\
\text { Loss }(\%)\end{array}$ & Limit State \\
\hline 5 & $<0.1$ & $<1$ & $0 / 3$ \\
\hline 4 & $0.1-1.16$ & $1-9$ & $1 / 3$ \\
\hline 3 & $1.16-3.34$ & $10-17$ & $2 / 3$ \\
\hline 2 & $3.34-11.6$ & $18-25$ & $3 / 3$ \\
\hline 1 & $>11.6$ & $>25$ & $4 / 3$ \\
\hline
\end{tabular}




\subsection{RESULTS}

\subsubsection{Corrosion Testing Program - Linear Polarization Resistance}

A total of four-hundred and seven (407) readings were taken across the structure. The following tables provide the analysis in accordance with the condition state rating for corrosion:

Table 4. Corrosion Rate Results Balconies and Balconettes

\begin{tabular}{|c|c|c|c|c|c|}
\hline \multirow[b]{2}{*}{$\begin{array}{l}\text { Condition } \\
\text { State }\end{array}$} & \multirow[b]{2}{*}{$\begin{array}{l}\text { Corrosion } \\
\text { Rate } \\
(\mu \mathrm{m} / \mathbf{y r})\end{array}$} & \multicolumn{2}{|c|}{ West End Elevation } & \multicolumn{2}{|c|}{ 88th Street Elevation } \\
\hline & & $\begin{array}{c}\# \text { of } \\
\text { readings } \\
(153)\end{array}$ & $(\%)$ & $\begin{array}{c}\# \text { of } \\
\text { readings } \\
(154)\end{array}$ & $(\%)$ \\
\hline 5 & $<0.1$ & 3 & 1.96 & 6 & 3.92 \\
\hline 4 & $0.1-1.16$ & 140 & 91.5 & 131 & 85.62 \\
\hline 3 & $1.16-3.34$ & 7 & 4.58 & 13 & 8.5 \\
\hline 2 & $3.34-11.6$ & 3 & 1.96 & 3 & 1.96 \\
\hline 1 & $>11.6$ & 0 & 0 & 0 & 0 \\
\hline
\end{tabular}

Table 5. Corrosion Rate Results Modillions

\begin{tabular}{|c|c|c|c|c|c|}
\hline \multirow[b]{2}{*}{\begin{tabular}{|l} 
Condition \\
State
\end{tabular}} & \multirow[b]{2}{*}{\begin{tabular}{|l} 
Corrosion \\
Rate \\
$(\mu \mathrm{m} / \mathrm{yr})$
\end{tabular}} & \multicolumn{2}{|c|}{ West End Elevation } & \multicolumn{2}{|c|}{ 88th Street Elevation } \\
\hline & & $\begin{array}{c}\# \text { of } \\
\text { readings } \\
(50)\end{array}$ & $(\%)$ & $\begin{array}{c}\text { \# of } \\
\text { readings } \\
(50)\end{array}$ & $(\%)$ \\
\hline 5 & $<0.1$ & 5 & 10 & 4 & 8 \\
\hline 4 & $0.1-1.16$ & 44 & 88 & 42 & 84 \\
\hline 3 & $1.16-3.34$ & 1 & 2 & 2 & 4 \\
\hline 2 & $3.34-11.6$ & 0 & 0 & 2 & 4 \\
\hline 1 & $>11.6$ & 0 & 0 & 0 & 0 \\
\hline
\end{tabular}

\subsubsection{Building Envelope Results}

A total of nine-hundred and eighty (980) readings were taken across the structure. The following tables provide the analysis in accordance with the condition state rating for corrosion:

Table 6. 3D Results Balconies and Balconettes

\begin{tabular}{|c|c|c|c|c|c|}
\hline \multirow[b]{2}{*}{$\begin{array}{l}\text { Condition } \\
\text { State }\end{array}$} & \multirow[b]{2}{*}{$\begin{array}{l}\text { Corrosion } \\
\text { Rate } \\
(\mu \mathrm{m} / \mathrm{yr})\end{array}$} & \multicolumn{2}{|c|}{ West End Elevation } & \multicolumn{2}{|c|}{ 88th Street Elevation } \\
\hline & & $\begin{array}{c}\# \text { of } \\
\text { readings } \\
(408)\end{array}$ & $(\%)$ & $\begin{array}{c}\# \text { of } \\
\text { readings } \\
(408)\end{array}$ & $(\%)$ \\
\hline 5 & $<0.1$ & 20 & 4.9 & 12 & 2.33 \\
\hline 4 & $0.1-1.16$ & 242 & 59.31 & 304 & 58.91 \\
\hline 3 & $1.16-3.34$ & 89 & 21.81 & 103 & 19.96 \\
\hline 2 & $3.34-11.6$ & 49 & 12.01 & 84 & 16.28 \\
\hline 1 & $>11.6$ & 8 & 1.96 & 13 & 2.52 \\
\hline
\end{tabular}

Table 7. 3D Results Upper L-Section Parapet Wall

\begin{tabular}{|c|c|c|c|c|c|}
\hline \multirow[b]{2}{*}{$\begin{array}{l}\text { Condition } \\
\text { State }\end{array}$} & \multirow[b]{2}{*}{$\begin{array}{l}\text { Corrosion } \\
\text { Rate } \\
(\mu \mathrm{m} / \mathbf{y r})\end{array}$} & \multicolumn{2}{|c|}{ West End Elevation } & \multicolumn{2}{|c|}{ 88th Street Elevation } \\
\hline & & $\begin{array}{c}\# \text { of } \\
\text { readings } \\
(18)\end{array}$ & $(\%)$ & $\begin{array}{c}\text { \# of } \\
\text { readings } \\
\text { (16) }\end{array}$ & $(\%)$ \\
\hline 5 & $<0.1$ & 13 & 72.22 & 6 & 37.5 \\
\hline 4 & $0.1-1.16$ & 4 & 22.22 & 10 & 62.5 \\
\hline 3 & $1.16-3.34$ & 1 & 5.56 & 0 & 0 \\
\hline 2 & $3.34-11.6$ & 0 & 0 & 0 & 0 \\
\hline 1 & $>11.6$ & 0 & 0 & 0 & 0 \\
\hline
\end{tabular}

Table 8. 3D Results Double L-Section Parapet Wall

\begin{tabular}{|c|c|c|c|c|c|}
\hline \multirow[b]{2}{*}{$\begin{array}{l}\text { Condition } \\
\text { State }\end{array}$} & \multirow{2}{*}{$\begin{array}{l}\text { Corrosion } \\
\text { Rate } \\
(\mu \mathrm{m} / \mathbf{y r})\end{array}$} & \multicolumn{2}{|c|}{ West End Elevation } & \multicolumn{2}{|c|}{ 88th Street Elevation } \\
\hline & & $\begin{array}{c}\text { \# of } \\
\text { readings } \\
(14)\end{array}$ & $(\%)$ & $\begin{array}{c}\# \text { of } \\
\text { readings (8) }\end{array}$ & $(\%)$ \\
\hline 5 & $<0.1$ & 3 & $21.43 \%$ & 0 & 0 \\
\hline 4 & $0.1-1.16$ & 8 & $57.14 \%$ & 8 & 100 \\
\hline 3 & $1.16-3.34$ & 2 & $14.29 \%$ & 0 & 0 \\
\hline 2 & $3.34-11.6$ & 1 & $7.14 \%$ & 0 & 0 \\
\hline 1 & $>11.6$ & 0 & $0.00 \%$ & 0 & 0 \\
\hline
\end{tabular}

\subsubsection{Results Summary}

Two methods were utilized in the in-depth inspection: the surface mounted testing on the façade of structure and the second deep within the building fabric. The surface measurements were inconclusive regarding the corrosion rate measurement, however the corrosion potential $\left(\mathrm{E}_{\text {corr }}\right)$ showed a realistic picture of corrosion activity occurring on the building. After successfully altering the test method to test within the building envelope an accurate assessment of corrosion was correlated between section loss, corrosion rates from which the team developed custom condition and limit states.

At the 88th St. balconies/balconettes, the potential provided an uncertain condition at $74 \%$ of the readings measured with an additional $5 \%$ with a $90 \%$ probability of corrosion. When comparing this with the $3 \mathrm{D} \mathrm{E}_{\text {corr }}$ the data is fined tuned and the uncertainty values lie at $35 \%$ instead of $74 \%$ and the probability of corrosion risk has only increased by $1 \%$. Overall the data with the $3 \mathrm{D} \mathrm{E}_{\text {corr }}$ clarified the original surface position of $79 \%$ of corrosion activity down to $41 \%$.

At the West End avenue balconies/balconettes, the potential provided an uncertain condition at $37 \%$ of the readings measured with an additional $16 \%$ with a $90 \%$ probability of corrosion. When comparing this with the $3 \mathrm{D} \mathrm{E}_{\text {corr }}$ the data sets have shifted and there is uncertainty at $41 \%$ instead of $37 \%$ and the probability of corrosion risk has decreased to $9 \%$ from $16 \%$. Overall the data with the $3 \mathrm{D} \mathrm{E}_{\text {corr }}$ clarified the original surface position of $53 \%$ of corrosion activity down to $50 \%$.

When comparing both elevations, a more accurate picture was provided by the $3 \mathrm{D} \mathrm{E}_{\text {corr }}$ at West End Avenue versus 88th St. The comparison provided an overall reduction of or risk of $38 \%$ at 88 th St. and only $3 \%$ at West End Avenue.

When summarizing the $3 \mathrm{D} \mathrm{I}_{\text {corr }}$ data, all data above Condition State 3 was deemed to indicate an obsolete component and required tile removal. These areas are regarded as corroded beyond acceptable section loss limits for the steel sub-component to function as designed. All data above Condition State 3 was assessed and considered as a contingency for repair rather than replacement. The contingency based on various condition states allowed the team to build in additional repair capacity by accounting for all corrosion activity, which will shift conditions.

Initially, the Local Law Façade Engineer had recommended that all projecting elements on the 
building be removed and replaced. After the testing program, damage was refined based on embedded steel condition and the overall recommendation for terracotta removal was based on corrosion activity rather than assumed deterioration. The values were obtained by taking an average of the three $\mathrm{I}_{\text {corr }}$ measurements from each side of the steel component. The evaluation of the values can be seen in Table 9, which provides the distribution of data for all areas.

In this table, the steel elements have been categorized by Condition States. State 5 and 4 require no action to be taken, Condition States 5 to 3 are areas where where the steel can be treated electrochemically (ICCP) as steel section is not beyond a structural limit state, and elements in Condition State 2 and 1 require intervention by physical repair or replacement.

Table 9. 3D Overall Summary

\begin{tabular}{|c|c|c|c|c|c|}
\hline \multicolumn{6}{|c|}{$88^{\text {th }}$ Street } \\
\hline Min & Max & $\begin{array}{l}\text { Number of } \\
\text { Readings }\end{array}$ & $\%$ & $\begin{array}{l}\text { Condition } \\
\text { State }\end{array}$ & Comments \\
\hline$<$ & 0.11 & 0 & 0 & 5 & \multirow{2}{*}{ No Action } \\
\hline 0.1 & 1.16 & 44 & 51.2 & 4 & \\
\hline 1.16 & 3.34 & 22 & 25.6 & 3 & $50 \%$ used \\
\hline 3.34 & 11.6 & 17 & 19.8 & 2 & \multirow{2}{*}{$100 \%$ Used } \\
\hline$>$ & 11.6 & 3 & 3.5 & 1 & \\
\hline \multicolumn{6}{|c|}{ West End } \\
\hline Min & Max & \begin{tabular}{|l} 
Number of \\
Readings
\end{tabular} & $\%$ & \begin{tabular}{|l} 
Condition \\
State
\end{tabular} & Comments \\
\hline$<$ & 0.11 & 0 & 0 & 5 & \multirow{2}{*}{ No Action } \\
\hline 0.1 & 1.16 & 37 & 54.41 & 4 & \\
\hline 1.16 & 3.34 & 23 & 33.82 & 3 & $50 \%$ used \\
\hline 3.34 & 11.6 & 7 & 10.29 & 2 & \multirow{2}{*}{$100 \%$ Used } \\
\hline$>$ & 11.6 & 1 & 1.47 & 1 & \\
\hline
\end{tabular}

The terra cotta tile summary for removal based on the corrosion inspection is as follows:

Table 10. Tile Removal Summary

\begin{tabular}{|l|l|l|}
\hline \multicolumn{2}{|c|}{} & Totals \\
\hline \multirow{4}{*}{$88^{\text {th }}$ Street } & Balconies & 2 \\
\cline { 2 - 3 } & Balconettes & 12 \\
\cline { 2 - 3 } & Terracotta Tiles & 114 \\
\cline { 2 - 3 } & Previously Removed & $12(10 \%)$ \\
\cline { 2 - 3 } & Recommended Removal & $14(12 \%)$ \\
\cline { 2 - 3 } & Contingency Removal & $7(6 \%)$ \\
\hline \multirow{5}{*}{$\begin{array}{l}\text { West } \\
\text { Avenue }\end{array}$} & Tiles Not Tested & $3(3 \%)$ \\
\hline \multirow{5}{*}{ End } & Tiles Not Removed & $81(71 \%)$ \\
\hline & Balconies & Totals \\
\cline { 2 - 3 } & Balconettes & 2 \\
\hline & Previously Removed & $12(\%)$ \\
\cline { 2 - 3 } & Recommended Removal & $5(12 \%)$ \\
\cline { 2 - 3 } & Contingency Removal & $10(8 \%)$ \\
\cline { 2 - 3 } & Tiles Not Tested & $35(29 \%)$ \\
\cline { 2 - 3 } & Tiles Not Removed & $103(84 \%)$ \\
\hline
\end{tabular}

\subsection{CONCLUSIONS}

The testing program successfully identified various conditions of the steel without the removal of the terra cotta elements. With a statistically high level of reliability established by collecting data from all projecting elements, it was determined that $65 \%$ of the embedded steel was in fair condition and did not require replacement based on the $3 \mathrm{D} \mathrm{I}_{\text {corr }}$ measurements The evaluation further provided information regarding degradation rates, modeling of future steel and masonry degradation, identified drivers of corrosion activity, and methods to reduce ongoing corrosion by limiting moisture ingress into the already compromised façade. In the end, the cost benefit to the client was a reduction of façade repairs, limiting the required amount of stripping necessary to treat the steel.

The overarching development of the condition states particular to the embedded steel component supporting the terra cotta tiles illustrates that an in-depth corrosion testing program, with a high level of calibration steel conditions, can reduce assumed repairs significantly.

The high level of detailed accuracy which can be gathered allows the team to determine rates of degradation, condition state modeling, and future performance while also fine-tuning repair programs that will minimize the impact of corrosion related degradation in the future.

\section{ACKNOWLEDGEMENTS}

The authors would like to thank the owners of the building, and the masonry contractor who provided swing stage support and assistance during the field program.

\section{REFERENCES}

1. P. Gibbs. Technical Advice Notes 20: Corrosion in Masonry Clad Early Steel Framed Buildings. (Edinburgh, Scotland. Historic Scotland: 2000). P.5

2. National Terra Cotta Society. Terra Cotta Standard Construction. Revised Edition. New York: NTCS: 1927).

3. Gerns, et. al. Understanding Terra Cotta Distress: Evaluation and Repair Approaches. Journal of Building Appraisal. Vol.2 No.4. (London, UK Palgrave MacMillan Ltd. 2007)

4. National Park Service. Preservation Briefs 7: The Preservation of Historic Glazed Architectural TerraCotta.

5. ASTM STP992. Diagnosis of Terra Cotta Glazed Spalling.

6. G. Crevello and M. Perez. "Terra Cotta Clad Steel Frame Building Repair Approach: Repair Options and Replacement Materials." Structure Magazine: May 2018.

7. C Gray. A Law and the Face of the City. New York Times. April 24, 2014.

8. Crevello, et al. Unpublished Client Reports. 
9. ASTM C876-2015 (Latest Revision) "Standard Test Method for Standard Test Method for Half-Cell Potentials of Uncoated Reinforcing Steel in Concrete". (West Conshohocken, PA; ASTM)

10. J. P. Broomfield. Corrosion of Steel in Concrete, 2nd Ed. (London: UK. Spon Press: 2007). 